Proceedings of the 2013 Winter Simulation Conference

R. Pasupathy, S.-H. Kim, A. Tolk, R. Hill, and M. E. Kuhl, eds

\title{
SIMULATION-BASED TRUCK FLEET ANALYSIS TO STUDY THE IMPACT OF FEDERAL MOTOR CARRIER SAFETY ADMINISTRATION'S 2013 HOURS OF SERVICE REGULATION CHANGES
}

\author{
Jeff Young \\ Engineering Team Leader \\ J.B. Hunt Transport, Inc. \\ Lowell, AR 72745, USA
}

\begin{abstract}
July 1, 2013 will usher in new revisions to the current Federal Motor Carrier Safety Administration's Hours of Service (HOS) regulations governing hours of service for drivers of Commercial Motor Vehicles. This paper will chronicle the modeling approach and preliminary results of the performance impact of the two most significant 2013 HOS regulation changes on a large random over-the-road (OTR) trucking fleet operating in North America. The ultimate goal of this modeling analysis was to provide data to quantify the pending impact of the regulation changes to guide company strategies to mitigate risk and provide a foundation for proactive customer communications. The simulation model was successfully validated by comparing simulated fleet performance against actual fleet performance. Results have been used to communicate impact to internal company stake holders, industry analysts, and customers, along with prompting detailed fleet studies to identify strategies to minimize impact to high risk customers..
\end{abstract}

\section{INTRODUCTION}

Truck drivers hours of service have been regulated for more than 70 years. During that time, there has been considerable research effort expended to identify ways to reduce highway injuries and fatalities involving commercial trucks. Landmark changes to hours of service regulations have been the results of this research. With the introduction of each revision to the HOS regulations, the Department of Transportation (DOT) attempts to consider the balance of business impact with public welfare and safety (Paul P. Jovanis, $\mathrm{Wu}$ and Chen 2011). However, as additions and changes make these regulations more complicated, determining the business impact increases in complexity. The DOT's Regulatory Impact Analysis (RIA) (Federal Motor Carrier Safety Administration 2011) provides an aggregated industry level assessment of the costs. The RIA states: "Though these costs are estimated using impacts on industry productivity, they would most likely be passed along as increases in freight transportation rates, and then ultimately to consumers in increased prices for the goods that are transported by truck". Concerned truckload carriers and shippers interested in how the pending regulation changes will impact their business have been left to their own devices to determine how these changes will impact their supply chain costs.

The stakeholders in public motor carriers and shippers share an interest in quantifying the impact the modifications to the HOS regulations will have on their companies supply chain performance and costs. It is clear that these changes to the scheduling rules will impact a motor carriers operations. These impacts include: "a redefined employee workday, a modified planning process to support the order to delivery capability and productivity changes" (Ervin and Harris 2004). The approach to evaluating these impacts will require analyzing how changes to a truck driver's work routine and available work hours will impact the productivity of fleet assets within the current order to delivery process. Modeling the simplest of transpor- 


\section{Young}

tation fleets is a formidable endeavor due to the innate complexity of resource scheduling to meet the dynamic requirements of the truck, driver, and shipper while adhering to the HOS regulations. Discrete event simulation is an ideal approach to model and analyze the influence of changing HOS regulations. It provides the necessary flexibility along with a way to incorporate the stochastic elements of the order to delivery process for a large OTR fleet.

This paper will chronicle the modeling approach and initial results for a discrete event simulation model that was used to evaluate the impact of changing HOS rules on a large OTR fleet operating in the continental U.S.A. Section 2 gives an overview of the pending changes to the Federal Motor Carrier Safety Administration's (FMCSA) HOS regulations along with a perspective on the trucking industry within the domestic U.S. transportation network. Section 3 will provide a more comprehensive description of this study's objective. Section 4 will outline the approach used to develop the simulation model. Model validation is then covered in Section 5. The results comparing a fleet operating under current HOS regulations versus the pending regulations along with a statistical interpretation of these results are given in Section 6. The conclusions generated from the model results are shown in Section 7.

\section{BACKGROUND}

\subsection{FMCSA HOS Regulation Changes}

The FMCSA since its establishment in 2001, has been tasked with "improving the safety of commercial motor vehicles and saving lives" (FMCSA n.d.). The FMCSA develops, maintains and enforces federal regulations to promote carrier safety. Among these regulations, part 395, regulates the hours of service of drivers for all motor carriers and drivers. These rules apply to drivers of commercial motor vehicles (CMV) which are defined by the FMCSA:

In general, a CMV is a vehicle that is used as part of a business and is involved in interstate commerce and fits any of these descriptions:

- Weighs 10,001 pounds or more

- Has a gross vehicle weight rating or gross combination weight rating of 10,001 pounds or more

- Is designed or used to transport 16 or more passengers (including the driver) not for compensation

- Is designed or used to transport 9 or more passengers (including the driver) for compensation

- A vehicle that is involved in Interstate or intrastate commerce and is transporting hazardous materials in a quantity requiring placards is also considered a CMV

The current FMCSA HOS regulations limit both driving and non-driving work hours. The regulations limit allowable drive and work hours at a driving shift, as well as a work week. Changes to these regulations have been implemented as recently as 2004. And like in 2004, the new changes in the HOS regulations attempt to address driver fatigue related accidents by limiting working hours and mandating rules related to required rest and time-off periods. In general, a drivers work and drive hours accumulate at both a shift and workweek level, with sleep hours and/or off duty hours that meet the regulations having the effect of resetting the accumulated drive and work hours to zero.

The U.S. Department of Transportation issued its final ruling on changes to the HOS regulations in December of 2011, along with a compliance date of July, 1, 2013. The revisions to the regulations will impact both the hours for a driving shift and work week. The driving shift will be impacted by the addition of a 30 minute "Rest Break" provision that counts against the total available work hours for the day. And the provision for hours off-duty required to reset logs has been modified to include two additional requirements. The current regulations along with the pending changes are summarized below in Table 1 . 


\section{Young}

Table 1: Hours of Service Rule Changes.

\begin{tabular}{|c|c|c|c|}
\hline \multirow{2}{*}{ Description } & \multicolumn{2}{|c|}{$\begin{array}{l}\text { FMCSA HOS } \\
\text { Regulations }\end{array}$} & \multirow{2}{*}{ Comment } \\
\hline & Current & $\begin{array}{c}\text { Starting } \\
7 / 1 / 2013 \\
\end{array}$ & \\
\hline $\begin{array}{l}\text { Off-Duty or Sleep Hours } \\
\text { Required between Shifts }\end{array}$ & 10 & 10 & No Change \\
\hline $\begin{array}{l}\text { Maximum On-Duty } \\
\text { Hours/Shift }\end{array}$ & 14 & 13.5 & $\begin{array}{l}\text { In a } 7 \text { day period, a driver can acculate no more than } 60 \text { work hours } \\
\text { before a } 34 \text { hour rest period is required. The } 34 \text { hour rest period } \\
\text { resets the drivers accumulated work hours to } 0 \text {. }\end{array}$ \\
\hline $\begin{array}{c}\text { Maximum Driving } \\
\text { Hours/Shift }\end{array}$ & 11 & 11 & $\begin{array}{l}\text { A driver can drive no more than } 11 \text { hours or accumlate } 13.5 \text { work } \\
\text { hours ( } 30 \text { minute rest break counts against total shift hours) before a } \\
10 \text { hour rest period is required. }\end{array}$ \\
\hline Rest Breaks & None & $30 \mathrm{Min}$. & $\begin{array}{l}\text { A driver may drive only If less than } 8 \text { hours have passed since the } \\
\text { end of a drivers last off-duty period of at least } 30 \text { minutes. }\end{array}$ \\
\hline $\begin{array}{l}\text { Maximum Weekly Hours } \\
\text { (7 Day Period) }\end{array}$ & 60 & 60 & No Change \\
\hline $\begin{array}{l}\text { Maximum Weekly Hours } \\
\text { (8 Day Period) }\end{array}$ & 70 & 70 & No Change \\
\hline $\begin{array}{l}\text { Hours Idle or Off-Duty } \\
\text { for Weekly Hours Reset }\end{array}$ & 34 & 34 & $\begin{array}{l}\text { Two new limitations have been added to the } 34 \text { hour restart: } \\
\square \text { Must include two periods between 1:00 a.m to 5:00 am } \\
\square \text { Mayonly be used once per week. }\end{array}$ \\
\hline
\end{tabular}

\subsection{Transportation Industry}

Trucking is the largest mode in both freight value and tonnage within the domestic U.S. transportation network (Margreta, Ford and Dipo 2009). Truck shipments account for $71 \%$ of the value and $69 \%$ of the tonnage of all shipments. Among the truck shipment volumes moved, 57\% is on for-hire trucks (trucks operated on behalf of - or by - a nongovernmental business entity that provides transportation services to its customers for compensation) while the remaining $43 \%$ is on private trucks (Private means that the truck is not available to any other business entity, nor the public, and is owned and/or operated by an individual, group, or nongovernmental business entity for its own purposes or benefits). The goods that are shipped on private trucks move on average much shorter distances, averaging $82 \mathrm{miles} / \mathrm{shipment}$ compared to $527 \mathrm{miles} / \mathrm{shipment}$ on for-hire trucks. At the average shipment lengths of haul, the for-hire truck segment of the domestic U.S transportation segment is operating under conditions that will be most impacted by the pending revisions to HOS regulations.

Carriers operating for-hire trucks, represents a significant number of the commercial vehicles operating across the continental U.S. transportation network. Large random over-the-road (OTR) trucking fleets make up a large percentage of the for-hire truck segment. Carriers operating this type of fleet operate in similar networks with load assignment and scheduling characteristics that are fairly uniform. By focusing on this segment of the domestic transportation infrastructure, the results of this study will provide some indication of how the changes to these regulations will impact a large segment of the transportation industry. 


\section{OBJECTIVE}

With a very limited perspective provided by FMCSA on the impact the new HOS changes will have on an individual carrier, J.B. Hunt Transport, Inc. needed to determine how these regulation changes will affect its fleet operations. The combination of rule changes in a dynamic fleet operating environment cannot be adequately analyzed using traditional deterministic methods of analysis. Past experience using discrete event simulation (Ervin and Harris 2004) to analyze fleet productivity impact due to changing HOS regulations, provided the insight, knowledge, experience and desire to undertake a project of this scope. The objectives of this study are:

1. Build an updated simulation model to analyze fleet operating performance with the existing and pending HOS rules to determine the likely impact of these rule changes on fleet utilization.

2. Identify strategies to ameliorate any adverse repercussions on fleet productivity.

\section{MODELING APPROACH}

The 2004 simulation study (Ervin and Harris 2004) was analyzed to determine the modeling approaches that could provide a framework for a new fleet simulation model. The six processes that were modeled in the 2004 study still represent the major processes necessary to model a fleet. These processes are:

1. Demand Generation

2. Capacity Management

3. Load and Tractor Assignment

4. Driver Log Management

5. Transportation Execution

6. Customer Freight Pick-up and Delivery.

Each of these six processes were reviewed to determine whether the supporting data and detailed approach to model the process were still valid. Processes from the 2004 study that were determined to still be valid had any supporting data or calculations updated where necessary. The customer freight pickup and delivery process was not modeled in detail and was instead incorporated into the transportation execution process. The remaining processes were revised and updated with the assistance of subject matter experts. Supporting data for process modeling parameters, attributes and logic, were compiled from the company's historical data warehouse.

The major processes encompass the major activities and functions within a fleet operation from shipment order creation through final delivery of a shipment. Each of these processes, the modeling approach along with compiled data used for model parameters, attributes and logic are discussed in the sections below.

\subsection{Demand Generation}

Demand in the context of this model represents a customer's shipment order or load. Demand was generated from historic shipment data for the random OTR fleet. The data represented a period of 27 weeks or just over 6 months. The shipment data contained 68,247 shipments with 11,188 distinct zip code to zip code lanes and 1,926 distinct zip locations. Each shipment contains data describing its origin, destination, loading and unload characteristics, length of haul in miles, pickup timing at the shipper, and delivery timing at the receiver. The shipment data was cleaned to repair or remove shipments with timing that clearly represented data entry errors or excessive durations due exceptions in the dispatch process such as timeoff included within the shipment.

As a departure from the 2004 HOS model, the historical pickup and delivery timing was used as the method of demand creation. This approach was taken to better match the shipment solicitation and book- 


\section{Young}

ing process. This process attempts to solicit and book shipments to best match delivery timing of the inbound truck and driver while minimizing the empty miles between shipments. The prior approach would preclude the solicitation and booking process and potentially distort both empty miles and lag time between truck and driver load assignments.

Loading and unloading data compiled for the historic shipments was analyzed and the probability distributions used to assign the delay hours were generated using Arena's Input Analyzer tool. The characteristics associated with load/unload process were used to segment the data into categories. These categories are live load/unload (driver backs into the dock and waits while the load is loaded/unloaded) and drop and hook (driver drops a trailer and pickups up a trailer that is already loaded or empty). The operational data associated with drop and hook loading at a shipper produced a probability distribution that did not fit with subject matter experts experience. A fixed value of 20 minutes was used to better approximate the expected time (because the delay associated with a drop and hook at a shipper is small, the required effort to obtain better sample data was determined to be unproductive). The load/unload hours for each shipment were assigned using the logic shown in figure 1 below.

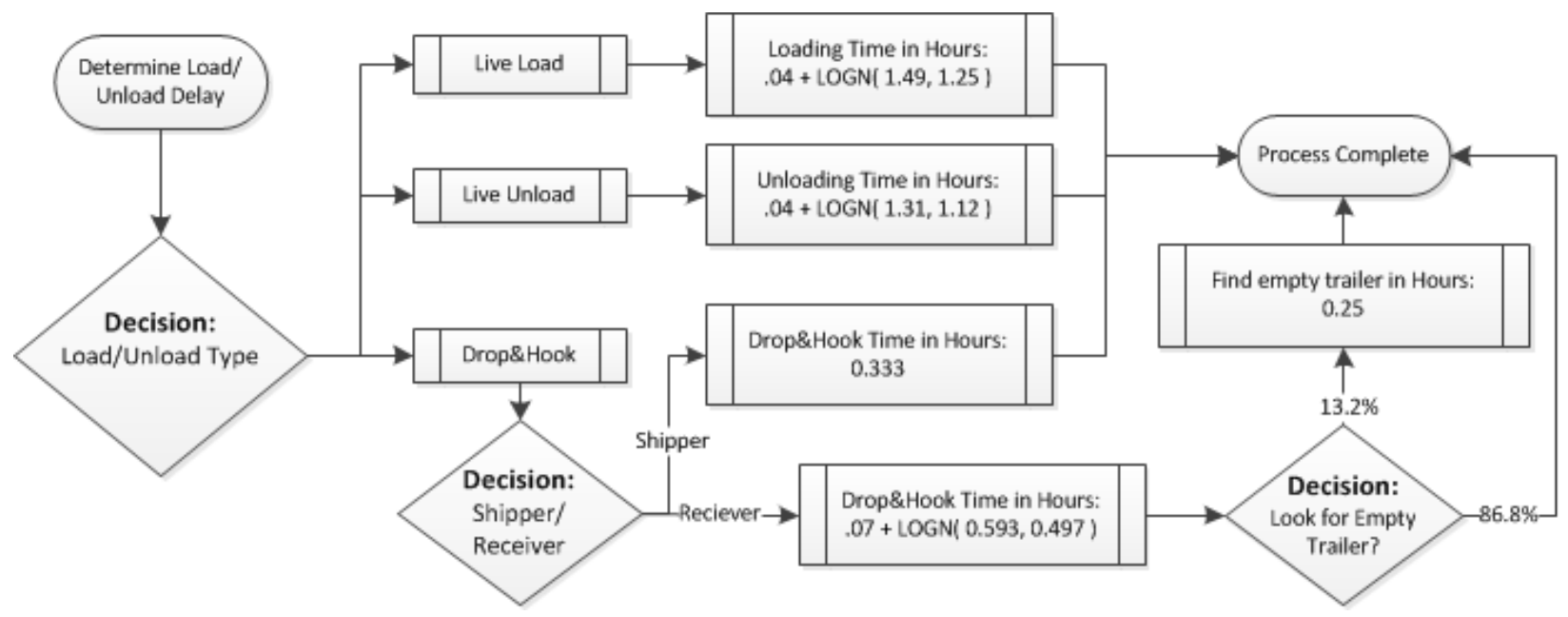

Figure 1: Load/Unload Delay Assignment Logic

Shipments were loaded into the simulation model as an entity with load characteristics including lane geography, dispatch timing, and length of haul. The loaded shipment entities are delayed until the earliest pickup time and are then gathered in a queue awaiting assignment to a driver.

\subsection{Capacity Management}

A driver centric approach was used to model the fleets activity in this random network. The truck and driver were modelled as a single entity because the focus of the model is the driver activity. To insure that the capacity in scarce markets did not outweigh demand, the number of drivers was calibrated by trial and error to match the average utilization of the fleet. From the over 1000 Drivers in original data, the final model used 750 drivers.

In addition to the requirement to abide by the HOS regulations, and customer shipping requirements, drivers due home schedules and geography must be considered. Driver turn-over in the OTR segment of the industry commonly exceeds $100 \%$ per year. Taking care of the driver and his family by honoring time-off request dates is critical in maintaining driver job satisfaction. The current data supported the probability distributions for time-off scheduling used in the 2004 fleet simulation model. This distribution is shown in table 2 below: 
Table 2: Hours of Service Rule Changes.

\begin{tabular}{|c|c|}
\hline Probability & $\begin{array}{c}\text { On-Duty Duration } \\
\text { Before Next Time-Off }\end{array}$ \\
\hline $9.2 \%$ & 1 Week \\
\hline $14.7 \%$ & 2 Weeks \\
\hline $30.5 \%$ & 3 Weeks \\
\hline $45.6 \%$ & 3 Weeks + EXPO $(9.67) / 7$ \\
\hline
\end{tabular}

The on-duty durations shown in Table 2 indicate the time a driver is away from his home domicile during a work cycle. This time includes drive, work, rest periods and off-duty time between dispatches and as required by the HOS regulations. Each driver is assigned a terminal location closest to his home where his time-off will begin and end. When a driver returns from a time-off period, a new time-off date and time was generated and then governs the next work cycle duration. The time-off date is a critical factor used in the load and driver assignment process.

To assign the time-off period, current time-off policy was used. Drivers are given 48 hours off for every week they are on duty. Partial weeks for drivers falling into the over 3 weeks on-duty category receive 6 days $+(2 / 7) \times \operatorname{EXPO}(9.67)$ days off.

At the completion of time-off, drivers are made immediately available to be planned on a load. The drivers will be dispatched from their assigned terminal. Because the truck and driver are modeled as a single entity, a truck is assumed to be immediately available for the driver.

Drivers were assigned a home domicile and initial load assignment based upon historical shipment data, and those drivers assigned domicile. All 750 drivers, were introduced into the model during the warm up period of two weeks with their next due home date randomly assigned at their first arrival.

\subsection{Load and Driver Assignment}

Modeling the logic behind load assignment process is the most difficult part of constructing a fleet simulation model. Balancing the needs of the driver, and the financial performance of the company while complying with the requirements of continually changing regulations, requires flexible and fairly complex logic. The planning logic incorporated into this model attempted, where possible, to follow current load planning optimization heuristics and process. Details related to the calculations required to quantify distances and times along with the assignment logic are discussed in the following sections.

\subsubsection{Calculations}

The geographic points associated with the availability of a driver and load are based upon the latitude and longitude of the destination of the completed load and the origin of the next load respectively. Mileage between the driver and potential loads is calculated using a formula that calculates the orthodromic distance between the given points using the spherical law of cosines formula shown in Figure 2. This formulations was used due to its simplicity and reasonably accurate results down to distances as small as a me- 


\section{Young}

ter (Veness 2002 - 2012). The transit time calculations for these distances use banded miles per hour (MPH) developed using historical transit data is shown in Table 3 and demonstrated in Figure 3.

\section{Spherical law \\ of cosines: $\quad d=\operatorname{acos}(\sin (\varphi 1) \cdot \sin (\varphi 2)+\cos (\varphi 1) \cdot \cos (\varphi 2) \cdot \cos (\Delta \lambda)) \cdot R$}

where $\varphi$ is latitude, $\lambda$ is longitude, $R$ is earth's radius (radius $=3963.19 \mathrm{mi}$ )

Figure 2: Orthodromic Distance Calculation.

Table 3: Banded MPH Calculation Table.

\begin{tabular}{|c|c|}
\hline $\begin{array}{c}\text { Mileage } \\
\text { Band }\end{array}$ & MPH \\
\hline 0 to 5 & 21.4 \\
\hline 5 to 10 & 30.0 \\
\hline 10 to 15 & 33.3 \\
\hline 15 to 20 & 37.5 \\
\hline 20 to 40 & 48.0 \\
\hline 40 to 60 & 54.5 \\
\hline$>60$ & 55.0 \\
\hline
\end{tabular}

For any distance, the speed in MPH shown in the Table 3 is used to calculate the transit time in hours for each mileage band. The times are calculated and summed until the full distance is represented. For example, for a distance of 61 miles the transit time is calculated as follows:

$$
\left(\frac{5}{21.4}\right)+\left(\frac{5}{30}\right)+\left(\frac{5}{33.3}\right)+\left(\frac{5}{37.5}\right)+\left(\frac{20}{48}\right)+\left(\frac{20}{54.5}\right)+\left(\frac{1}{55}\right)=1.49 \text { hours }
$$

Figure 3: Sample Transit Time Calculation with Banded Miles.

\subsubsection{Modeling Logic}

The VBA(Microsoft Visual Basic $_{\circledast}$ for Applications) block in Arena, provides a module that can contain very complex logic which is fired off by a models entities. This block is ideal to contain the load and driver planning logic and provided new capabilities to simplify the complexity of the fleet simulation model not available in the 2004 Fleet model. The choice of which entity to fire the process was not as straight forward as if first seems. Choosing either entity creates modeling issues that will ultimately affect the optimality of the assignment, negatively impact the balance between the needs of the driver and operational performance or slowing model runtimes by requiring the solutions space for each assignment to be increased considerably.

The initial version of this model had the load entity firing off the assignment process. It was eventually abandoned for a number of reasons. The logical use of an expanding geographic search for the first feasible driver, is insensitive to driver's needs. Drivers with longer idle times or nearing time-off that are farther away from a loads origin are often passed over further aggravating the situation. Secondly, the availability of the order dictates the order of assignment and limits the optimality compared to consider- 


\section{Young}

ing the assignment of other loads in the geographic area with the same set of drivers. The insensitivity to the needs of the driver (the focus of this study) ultimately drove the decision to abandon this approach

To insure that the load planning process put the focal point on the driver, its entity was chosen to fire off the process. Though it is recognized that this approach suffers from the same geographic global optimality problems as using the load to fire off the load planning event, the simplicity and affinity for the model focus made it the best choice.

Each available driver fires the load planning process following the end of his current dispatch or following time-off. Using the expanding geographic search for feasible load assignments, the feasibility of an assignment is checked, with feasible assignments receiving a cost. The minimal load assignment is then assigned and the driver is dispatched.

Multiple feasibility checks are performed for every potential assignment. The driver's ability to both pick up and deliver the load on-time considering empty transit from prior load, DOT hours and break requirements. Additionally, load assignments are checked to make sure that they will not prevent a driver from getting to his home terminal in time to meet the time-off start time.

For each feasible load assignment, a cost was assigned. It includes estimated real world costs along with penalty costs. The estimated real world costs are empty miles. These include the miles required to get from a receiver to the shipper on the driver's next dispatch, as well as, empty miles that may be required to get a driver home at the completion of the assignment. The penalty costs included for the loss of time. Lost time can occur between dispatches, and within dispatches with large amounts of dispatch flex (which represents the time between when a load is available and when it must be picked up to make ontime delivery). An additional penalty cost was added to load assignments that occur within 4 days of a driver's time-off. This penalty included the empty miles from the load's destination to the driver's domicile times a factor that escalated as the number of days until the driver's time-off start. The mileage and penalty costs used in this model are shown in the Table 4 below:

Table 4: Assignment Costs.

\begin{tabular}{|c|c|}
\hline Type & Cost \\
\hline Mileage & \$1.50 Per Mile \\
\hline Wait & $0.5 \times\left(\left(12 \times\right.\right.$ WaitHours $\left.{ }^{2}\right)-(10 \times$ WaitHours $\left.)+4\right)$ \\
\hline Due Home & 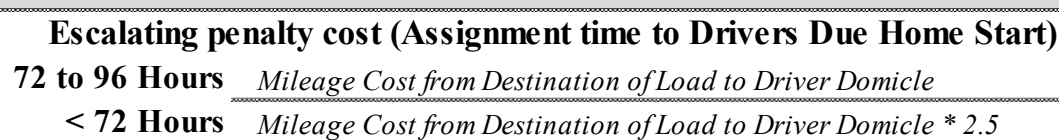 \\
\hline
\end{tabular}

Finally, the driver is assigned the minimum cost assignment. The mileage cost addresses the financial needs of the business. The wait time penalty and due home costs addresses both the driver and the business need to be productive, and insure that the driver's due home needs are met at a minimal cost.

\subsection{Driver Log Management}

Managing driver's log hours is critical to nearly all processes in this model. Model logic related to capacity management, load and driver assignment and transportation execution are dependent upon the driver's accumulated work and drive hours. To insure that the requirements of the HOS regulations are enforced, work and drive hours were recorded for each driver for the current 24 hour period along with the prior week. Additionally, for the new HOS regulations the time of the last 30 minute break and 34 hour reset were tracked at the driver level. The rest and 10 hour breaks along with 34 hour resets were recorded for the purposes of analysis comparisons. 


\section{Young}

Following the assignment of a load or time-off, the driver's logs were updated, shifting the recorded data to the current clock time. Each break event is recorded prior to the shifting of the 7 day sliding weekly data record. These updates occurs in accordance with the needs of the load assignment process.

\subsection{Transportation Execution}

Following the load assignment and dispatch, the driver picks up the load, travels to the destination, and then delivers the load. Required breaks for either rest or sleep are factored into the total duration of the assigned load. The transit time from the shipper to the receiver is calculated using the banded MPH formula illustrated in Table 3 and Figure 2. Drivers begin and end a work cycle (between time-off) at their home domicile.

\section{MODEL VALIDATION}

The model was run for a period of 27 weeks. Output data was compared directly to historical log data. Model adjustments were made as necessary until the performance of the model fleet closely resembled the historical log data. The average log hours and miles per week, along with the distribution of total $\log$ hours were compared (partial work weeks for both historical and simulation output were removed). The results of this comparison are shown in Table 5 below:

Table 5: Simulation Validation.

\begin{tabular}{|c|c|c|c|c|c|c|}
\hline & \multirow{2}{*}{\multicolumn{2}{|c|}{$\begin{array}{l}\text { Historical } \\
\text { Log Data }\end{array}$}} & \multicolumn{4}{|c|}{ Simulation } \\
\hline & & & \multicolumn{2}{|c|}{ Current HOS } & \multicolumn{2}{|c|}{ New HOS } \\
\hline & Count & $\begin{array}{l}\% \text { of } \\
\text { Total }\end{array}$ & Count & $\%$ of Total & Count & $\begin{array}{l}\% \text { of } \\
\text { Total }\end{array}$ \\
\hline \multirow{4}{*}{$\begin{array}{r}\text { Less Than } 40 \\
\text { Between } 40 \text { and } 50 \\
\text { Between } 50 \text { and } 60 \\
\text { Greater Than } 60\end{array}$} & 3,334 & $31.5 \%$ & 4,293 & $38.7 \%$ & 4,370 & $40.5 \%$ \\
\hline & 3,397 & $32.1 \%$ & 4,268 & $38.5 \%$ & 4,129 & $38.3 \%$ \\
\hline & 3,271 & $30.9 \%$ & 2,409 & $21.7 \%$ & 2,195 & $20.4 \%$ \\
\hline & 586 & $5.5 \%$ & 128 & $1.2 \%$ & 84 & $0.8 \%$ \\
\hline \multirow[b]{2}{*}{ Average Weekly } & Miles & Hours & Miles & Hours & Miles & Hours \\
\hline & 1,977 & 43.7 & 1,979 & 43.8 & 1,972 & 43.4 \\
\hline
\end{tabular}

Comparison results show very close utilization and hours. The distribution of fleet hours were similar with the historical log data showing more drivers at the higher log hours per week bands.

\section{RESULTS}

The comparison of simulation output between the current and new HOS fleet models showed discernable differences. Key performance differences were compared between the two models using Single Factor ANOVA in Microsoft Excel. ANOVA was not performed on Miles/Workday, 34 Hour Reset Hours, and weekly rest hours. Statistically relevant differences were seen in average driver utilization and 34 Hour reset hours. On average a driver can expect to lose 22 miles and a reduction in available work hours of 0.68 or 41 minutes per week. The comparison of the two models can be seen in Table 6 below. 


\section{Young}

Table 6: Simulation Model Comparison.

\begin{tabular}{|c|c|c|c|c|c|}
\hline & \multicolumn{2}{|c|}{ Weekly Averages } & \multicolumn{2}{|c|}{ Change } & \multirow{2}{*}{$\begin{array}{c}\text { Probability of No } \\
\text { Statistical } \\
\text { Difference } \\
\end{array}$} \\
\hline & $\begin{array}{c}\text { Current } \\
\text { HOS }\end{array}$ & $\begin{array}{l}\text { New } \\
\text { HOS }\end{array}$ & Difference & $\begin{array}{c}\% \text { of } \\
\text { Current }\end{array}$ & \\
\hline Miles Per Week & 1,622 & 1,600 & -22.13 & $-1.36 \%$ & $0.2 \%$ \\
\hline Miles Per WorkDay & 324.4 & 320.0 & -4.43 & $-1.36 \%$ & \\
\hline Loads Per Week & 3.10 & 3.05 & -0.05 & $-1.63 \%$ & $0.001 \%$ \\
\hline 34 Hour Reset Hours & 1.45 & 5.0 & 3.56 & $245.66 \%$ & \\
\hline Weekly Rest Hours & 0.00 & 1.93 & 1.93 & & \\
\hline 10 Hour Break Hours & 15.93 & 15.7 & -0.27 & $-1.68 \%$ & $1.7 \%$ \\
\hline Weekly Total Hours & 36.18 & 35.50 & -0.68 & $-1.88 \%$ & $0.0005 \%$ \\
\hline
\end{tabular}

*ANOVA not performed on Miles/Workday, 34 Hour Reset Hours, and weekly rest hours.

CONCLUSION

The impact of the changing HOS regulations may seem to be insignificant, but the potential consequences of these changes will be apparent to commercial motor vehicle carries and drivers alike. The profitability of these carriers may be impacted by the loss in fleet utilization. While, drivers will be hit with a work environment that is increasingly hard to earn the wages that make the time away from home worthwhile. Ultimately, someone will need to pay.

Changes to truck/driver utilization may seem inconsequential in magnitude, the potential impact in an asset heavy business can be quite significant. Small increases in utilization can provide significantly higher bottom line revenue. Many carriers in this industry have struggled over the years to stay in business with the pressures of increasing insurance and fuel costs along with a shrinking driver pool. Carriers wanting to survive will need to understand how and where these changes will impact them to develop strategies to cope.

Drivers in this industry have a very tough job. Long periods of time away from home and long hours. These drivers should expect wages that compensate them adequately for the sacrifices they make. Because their wages are derived by the miles they drive, changes to their ability to get miles will result in a degradation of their compensation. Without industry wide per mile increases, a change like this will continue to make this job less and less attractive.

The rippling effect of these regulation changes will clearly end up in the lap of the consumer. As stated in the FMCSA's regulatory impact analysis these costs "... would most likely be passed along as increases in freight transportation rates, and then ultimately to consumers in increased prices for the goods that are transported by truck." But before the ripple of this change is felt by the consumer, carriers, drivers and shippers will need to be ready to minimize the impact to them.

\section{ACKNOWLEDGMENTS}

The creation of a model like this (no matter how imperfect), takes a lot of time and effort. There is an unending list of things that could be continually investigated and fined tuned. As such, I would like to thank the following individuals for their important contributions to this effort. I would like to thank Guven Kaya for his help in researching methods to quickly calculate huge number of distances required by this model along with his insightful code debugging help. I would also like to thank Eddie Sahakian for his help in wading through the data to pull from it the load/unload distributions for this model. And finally, I would like to thank Eric Ervin for providing the valuable insights from the prior fleet modeling work. 


\section{REFERENCES}

Ervin, Eric, and Russ Harris. 2004. "Simulation Analysis of Truck Driver Scheduling Rules." In Proceedings of the 2004 Winter Simulation Conference. Edited by M. D. Rossetti, J. S. Smith, and B. A. Peters, eds. R .G. Ingalls.

Federal Motor Carrier Safety Administration. 2011. 2010-2011 Hours of Service Rule Regulatory Impact Analysis. Accessed May 1, 2013.

http://www.fmcsa.dot.gov/documents/hos/2011_HOS_Final_Rule_RIA.pdf.

Federal Motor Carrier Safety Administration. Our ${ }^{-}$Mission. ${ }^{-}$Accessed May 1, 2013. http://www.fmcsa.dot.gov/about/what-we-do/mission/mission.htm.

Margreta, Michael, Chester Ford, and M. Adhi Dipo. 2009. U.S. Freight on the Move: Highlights from the 2007 Commodity. Special Report. Accessed May 1, 2013. http://2bts.rita.dot.gov/publications/special_reports_and_issue_briefs/special_report/2009_09_30/ pdf/entire.pdf.

Paul P. Jovanis, Ph.D., Kun-Feng Wu, and and Chen Chen. 2011. Hours of Service and Driver Fatigue: Driver Characteristics Research. Final Report, Larson Transportation Institution, Penn State University, Washington, DC: U.S. Department of Transportation, 88. Accessed May 1, 2013. http://www.fmcsa.dot.gov/facts-research/research-technology/report/HOS-Driver-Fatigue.pdf.

Veness, Chris. 2002. Calculate distance, bearing and more between Latitude/Longitude points. Accessed May 1, 2013. http://www.movable-type.co.uk/scripts/latlong.html.

\section{AUTHOR BIOGRAPHIES}

JEFF YOUNG is an Engineering Manager with JB Hunt Transport, Inc. in Lowell, AR. He received a Bachelor of Science in Industrial Engineering from Purdue University in 1991 and a Master of Science in Industrial Engineering with emphasis in Simulation from Purdue University in 1995. Jeff has been with J.B. Hunt Transport Inc. for 12 years and has another 8 years of work experience in manufacturing, third party logistics, and supply chain analysis. His email address is jeff_young@jbhunt.com. 